\title{
DEFECTS AND LOCALIZED STATES IN SILICA LAYERS IMPLANTED WITH LEAD IONS
}

\author{
A.F. Zatsepin ${ }^{1}$, H.-J.Fitting ${ }^{2 *}$, E.A. Buntov ${ }^{1}$, V.A. Pustovarov ${ }^{1}$, B. Schmidt ${ }^{3}$ \\ 1) Ural Federal University, Phys.-Tech. Institute, Mira 19, 620002 Ekaterinburg, Russia \\ 2) University of Rostock, Institute of Physics, Universitaetsplatz 3, D-18051 Rostock, Germany \\ 3) Research Center Dresden Rossendorf, Institute of Ion Beam Physics, POB 510119, \\ D-01314 Dresden, Germany
}

The luminescence of silica films and glasses implanted with $\mathrm{Pb}^{+}$ions was studied by means of time-resolved photoluminescence spectroscopy under synchrotron excitation. The ion-modified silica layers are "metal-dielectrics" composites the oxide part of which is represented by amorphous micro-heterogeneous phase with variable $\mathrm{Pb}^{2+}$ ions. Two groups of emission centers are identified: such as: (1) radiation-induced oxygen-deficient centers (ODCs) and non-bridging oxygen atoms (NBOs) in the $\mathrm{SiO}_{2}$ matrix and (2) localized electronic states (LS) of the amorphous lead-silicate phase.

* corresponding author: phone +49-381-498 6760 , fax: +49-381-498 6802

email: hans-joachim.fitting@uni-rostock.de

\section{Introduction}

The nanosized "metal-dielectrics" composites have unique properties that ensure their suitability for optical switching networks: a large third-order nonlinear response, picosecond switching times and relaxation, thermal and chemical stability, high laser damage threshold, and low two-photon absorption [1]. Disclosed composites can be prepared in various ways. For example, ion implantation is a versatile technique that allows well-controlled introduction of various elements in a solid matrix. Changing the ion implantation parameters (type and energy of the ions, target material, temperature, etc.) allows achieving the desired characteristics of the resulting materials. In recent decades, a method was used in particular for the synthesis of lead silicate composites [2,3], having a nonlinear refractive index and the response time of a picosecond order [1].

Both the bulk matrices and thin films may be processed using the ion implantation [2, 3 and 4]. Known analogous bulk systems, such as a lead silicate glasses, are widely used as optical lenses, electronic and optoelectronic devices due to their high refractive index, high secondary electron emission and a low melting point [5]. At the same time nanostructured silicon dioxide layers are of great interest as active waveguide elements for modern microand optoelectronics. Their modification by ion-beam synthesis offers the prospect of creating microminiature light sources and optical switchers [6]. The variety of possible bond types 
between the atoms of silicon, oxygen, and lead determines the features of luminescence and optical properties of such systems [7-12]. Therefore ion-beam treatment requires careful consideration of the many processes accompanying ion-irradiated material fabrication.

Improving the properties of functional materials based on lead-silicate nanocomposites obtained by ion implantation will be not possible without a detailed study of the nature of radiation defects and electronic excitations. The peculiarities of modification of the $\mathrm{SiO}_{2}$ implanted with IV and VI group ions and properties of point defects formed during implantation were studied in our previous papers: $[13,14]\left(\mathrm{Si}^{+}\right.$ions $),[15]\left(\mathrm{Ge}^{+}\right.$implantation), [16] $\left(\mathrm{Sn}^{+}\right.$bombardment), [17, 18] (selenium ions) and [19] (sulfur). The present article is devoted to the study of the energy structure of luminescence centers in the silica films and glasses implanted with lead ions by means of low-temperature time-resolved photoluminescence excited by synchrotron radiation pulses.

\section{Experimental}

The objects under study were $\mathrm{SiO}_{2}$ films of $500 \mathrm{~nm}$ thick thermally grown on a silicon substrate of p-type and subjected to $\mathrm{Pb}^{+}$ion implantation with energy of $150 \mathrm{keV}$ and a fluence of $5 \cdot 10^{16} \mathrm{~cm}^{-2}$. Then films were annealed in a dry nitrogen atmosphere at $900{ }^{\circ} \mathrm{C}$ for one hour. The second type of samples were silica glasses of $\mathrm{KV}$ type implanted with $\mathrm{Pb}^{+}$ions $\left(\mathrm{E}=30 \mathrm{keV}, \mathrm{F}=5 \cdot 10^{16} \mathrm{~cm}^{-2}\right)$. The irradiation and excitation was performed in repetitively pulsed mode with pulse duration of $0.4 \mathrm{~ms}$ and a frequency of $25 \mathrm{~Hz}$. The current density in a pulse was $0.6 \mathrm{~mA} / \mathrm{cm}^{2}$.

The photoluminescence (PL) spectra in the region of 1.5-5.0 eV, PL excitation spectra in the region of 3.7-16 eV (0.32 nm spectral resolution) and PL decay kinetics were measured under selective excitation of vacuum ultraviolet synchrotron radiation (SR) at the SUPERLUMI station (HASYLAB, DESY, Hamburg) [20]. Samples were mounted in a sample holder attached to a He-flow cryostat with vacuum not less than $7 \cdot 10^{-10}$ Torr. At the storage ring DORIS the full width at half maximum (FWHM) of SR pulses was 130 ps with the repetition period of $192 \mathrm{~ns}$. Such pulses excitation enables the recording of spectra within a time-window correlated with the arrival of SR pulses. In the present experiments we recorded time-resolved spectra within two independent time-windows (TWs) set for detection of luminescence signal within $0.8-18 \mathrm{~ns}$ (TW1) and 52-140 ns (TW2) relative to the start of the SR pulse. Time-integrated (TI) spectra were recorded within the full time range available between two sequential excitation pulses, i.e. up to $192 \mathrm{~ns}$. 
The convolution method was used to analyze fast components of the PL decay kinetics. The time resolution of the whole detection system was $1 \mathrm{~ns}$. The PL spectra were recorded using the $0.3 \mathrm{~m}$ monochromator ARC Spectra Pro-308i and the photomultiplier R6358P (Hamamatsu). PL excitation spectra were normalized to an equal number of exciting photons using sodium salicylate.

\section{Results}

The resulting implantation profiles for films and glass matrices are shown on Fig. 1, a. Silicon dioxide implanted with lead ions is actually a non-homogenous system and may contain in structure several zones with lead content varying from pure silica to metal lead clusters (Fig. 1, b). Transition regions $x \mathrm{PbO} \cdot(1-x) \mathrm{SiO}_{2}$ with variable lead concentrations can be formed between the clusters and the surrounding matrix. An intermediate zone $\mathrm{PbO}-\mathrm{SiO}_{2}$ includes silica with a low content of $\mathrm{Pb}$ atoms and modified by the bonds of $\mathrm{Si}-\mathrm{O}-\mathrm{Pb}$ [9-11]. A zone near $\mathrm{Pb}$ cluster may form amorphous silicates with high lead content, which are characterized by the presence of $\mathrm{PbO}_{\mathrm{n}}$ groups and bridging fragments $\mathrm{Pb}-\mathrm{O}-\mathrm{Pb}$. Several types of structural groups involving different states of oxygen atoms have been found in the lead silicate glasses $[9,11]$. These groups are assigned to the bridging oxygen $\mathrm{Si}-\mathrm{O}-\mathrm{Si}(\mathrm{BO})$, the non-bridging oxygen $\mathrm{Si}-\mathrm{O}-\mathrm{Pb}(\mathrm{NBO})$ and an oxygen atom, associated with two lead atoms $\mathrm{Pb}-\mathrm{O}-\mathrm{Pb}(\mathrm{MBO}-$ metal bridging oxygen $)$.

The $\mathrm{SiO}_{2}$ matrix subjected to ion implantation becomes a heterogeneous medium containing metal nanoclusters $\mathrm{Pb}-\mathrm{nc}$, silica point defects $\left(\mathrm{ODC}, \mathrm{Pb}^{2+}\right)$ and localized electronic states (LS) of $\mathrm{Pb}^{2+}$ type in the amorphous transitional microphases of variable composition (including $\mathrm{Si}-\mathrm{O}-\mathrm{Pb}$ and $\mathrm{Pb}-\mathrm{O}-\mathrm{Pb}$ fragments) between lead nanoclusters and pure $\mathrm{SiO}_{2}$ (Fig. 1, b).

The PL spectra excited by photons with energy of $6.9 \mathrm{eV}$ contain at least four elementary bands at $4.1 \mathrm{eV}, 3.1 \mathrm{eV}, 2.6 \mathrm{eV}$ and $2.2 \mathrm{eV}$ (Fig. 2). The bands 4.1 and $2.2 \mathrm{eV}$ are characterized by the PL decay kinetics of the nanosecond range (Fig. 3), while the rest of the bands have decay times in the microsecond range. The peak at $3.1 \mathrm{eV}$ does not change its intensity when the temperature is raised to $290 \mathrm{~K}$, while long wavelength bands undergo significant quenching of photoluminescence at room temperature (see Fig. 2).

Analysis of PL excitation spectra (Fig. 4) shows that a maximum of $3.1 \mathrm{eV}$ is excited most efficiently in the 5.3 and $7.6 \mathrm{eV}$ range. In this case, the intermediate excitation band around $6.7 \mathrm{eV}$ appears due to spectral overlap with the intense photoluminescence peak of 2.6 $\mathrm{eV}$. In PL excitation spectra the bands $2.6 \mathrm{eV}$ and $2.2 \mathrm{eV}$ have the highest intensity when 
excited by photons with energy of $6.1 \mathrm{eV}$ and $7.8 \mathrm{eV}$. The low-energy $\mathrm{UV}$ excitation of $3.7 \mathrm{eV}$ to slightly activates three radiative transitions $2.2 \mathrm{eV}, 2.6 \mathrm{eV}$ and $3.1 \mathrm{eV}$ (Fig. 5). The short PL decay kinetics (decay time of $8.7 \mathrm{~ns}$ ) is observed upon excitation of the $2.18 \mathrm{eV}$ PL band in the $3.7 \mathrm{eV}$ spectral region (Fig. 6).

The $\mathrm{SiO}_{2}$ films implanted with lead ions show a similar spectrum of photoluminescence (Fig. 7 a), which comprises three Gaussian components located at 2.2, 2.6 and $3.3 \mathrm{eV}$. The decay time for all the peaks lies in the microsecond range under high-energy excitation $7.3 \mathrm{eV}$ PL. The excitation spectra of these bands have a complex shape with multiple peaks around $5.3,6.3,9.5$, and $11.7 \mathrm{eV}$. The same set of peaks in the excitation spectra is shown, probably due to spectral overlap of inhomogeneously broadened PL bands. The most efficient excitation of the $2.6 \mathrm{eV}$ band is observed in the region of $11.7 \mathrm{eV}$, i.e. in the excitation region of $\mathrm{SiO}_{2}$ excitons. At the same time the $3.35 \mathrm{eV}$ PL band is best excited in the region of 5.3 $\mathrm{eV}$, characteristic for the singlet-singlet transition of oxygen-deficient centers in the $\mathrm{SiO}_{2}$ matrix.

The experimental results allow us to interpret the observed PL as a manifestation of the three types of luminescence centers. The PL maximum at $4.2 \mathrm{eV}$ (Fig. 2), which has a relatively low intensity and a characteristic monoexponential PL decay kinetics with $\tau=8.7$ $\mathrm{ns}$, is close to a singlet transition in ODC centers $(4.3-4.4 \mathrm{eV})$. From the comparison of the PL and PLE excitation one can conclude that this PL area is significantly reabsorbed by the charge-transfer band $\mathrm{O} 2 \mathrm{p} \rightarrow \mathrm{Pb} 6 \mathrm{p}(3.75 \mathrm{eV})$, which may account for a small red shift of the singlet peak. The band $3.1 \mathrm{eV}$ (Fig. 2) in the implanted silica glass corresponds to the singlettriplet electronic transition of $\beta$-ODC centers in the $\mathrm{SiO}_{2}$ matrix [12].

A similar triplet luminescence band in $\mathrm{SiO}_{2}$ films undergoes a blue shift to the region of $3.3 \mathrm{eV}$. One can suggest that in the non-homogeneous system with a developed surface formed as a result of implantation, we observe ODC centers modified by the presence of $\mathrm{Pb}$ atoms. So the photoluminescence band range $2.9-4.5 \mathrm{eV}$ corresponds to point defects of the $\mathrm{SiO}_{2}$ matrix with a low lead content. Thus silica glass and $\mathrm{SiO}_{2}$ films, both implanted with lead ions, exhibit similar sets of emission centers assigned by different spectral and kinetic characteristics. Interpretation may be associated with the presence of the implanted matrix phases with varying lead content.

\section{Discussion}

The maximum at $2.6 \mathrm{eV}$, which is found in the PL spectra of implanted glasses and films, seems to belong to the luminescence of the $\mathrm{Pb}$ localized states in the low-lead region $(x$ 
$<0.5$ ). This is indicated by the coincidence of the band maximum in the PL spectrum and the excitation region of the PL (3.7-4.0 eV) with the same characteristics in the lead-silicate glasses, previously studied in [11]. The $2.6 \mathrm{eV}$ PL band is due to an electronic transition $6 \mathrm{p} \rightarrow$ 6s of the $\mathrm{Pb}$ atoms [10]. This intracenter transition can occur in $\mathrm{Pb}$ atoms, dissolved in the $\mathrm{SiO}_{2}$ matrix. The excitation spectrum of the PL band (Fig. 4) has a non-elementary shape and reaches its maximum intensity in the $5.5-8.5 \mathrm{eV}$ region. It consists of four peaks which are associated with $6 \mathrm{~s} \rightarrow 6 \mathrm{p}$ transitions in $\mathrm{Pb}$ atoms.

The structure of the outer electron levels of $\mathrm{Pb}^{2+}$ ions is well known and is described by the Seitz model [21]. Four bands are observed in the optical absorption spectra of these ions, corresponding to $6 \mathrm{~s} \rightarrow 6 \mathrm{p}$ transitions and designated A, B, C and D (see inset in Fig. 8). A recent compilation of data on the spectral parameters of lead ions in ionic crystals [22] made it possible to establish the correlation dependence between the position of the bands and the magnitude of the environmental factor $h$ :

$$
h=\sqrt{N f_{c} \alpha},
$$

where $N$ - ion coordination, $f_{c}$ - the fraction of covalence of chemical bond, $\alpha$ - the bulk polarizability of bond. The correlations obtained in [22] (thick solid line in Fig. 8) perform well for a wide range of ionic crystals in a range of $h=0.4-0.7$. Comparison of the excitation peak positions (Fig. 4) with the dependencies allowed to determine the effective value of the environmental factor $h=0.413$ in case of glass and interpret peaks $6.1,6.9$ and $7.7 \mathrm{eV}$ as $\mathrm{Pb}^{2+}$ ion transitions $\mathrm{B}, \mathrm{C}$ and $\mathrm{D}$, respectively.

According to our calculations, the A band should be observed around $5 \mathrm{eV}$, but this transition often has a very low oscillator strength and cannot be distinguished well in the experimental spectra, [23]. The equation (1) is proposed for ionic crystals and may have a different view in the case of covalent-ionic bonds in the amorphous $\mathrm{SiO}_{2}$. This is confirmed by the low value of the polarizability $0.1 \AA^{3}$, calculated from the equation (1). However, as can be seen from Fig. 7 (filled circles) the overall trend is valid for lead in silicon dioxide glass.

Implanted $\mathrm{SiO}_{2}$ films demonstrate higher values of environmental factor $h$. The specific feature of the films is also the lack of precise $h$ value: the intersection points (clear circles) positions depend on the energy level. This difference may be caused by post-implantation annealing, performed on films, which lead to a tighter packing of implanted ions and therefore to a greater coordination numbers. High energy of implanted ions chosen for silica films produces broad implantation profile (Fig. 1), introducing large dispersion of spectroscopic 
parameters in the emission centers statistical ensemble. Such broad distribution may explain both the nonselective character of PLE spectrum (Fig. 7, b) and spreading of environmental factor $h$ values for $\mathrm{SiO}_{2}$ films (Fig. 8) that prevent accurate Gaussian deconvolution of the PLE spectrum of complex shape (Fig. 7, b).

Photoluminescence band in the region of $2.2 \mathrm{eV}$ has complex decay kinetics: a fast dominant component with $\tau=8.7 \mathrm{~ns}$ and a slow component with $\tau>1 \mu \mathrm{s}$. The fast component is excited most efficiently in the $\mathrm{O} 2 \mathrm{p} \rightarrow \mathrm{Pb} 6 \mathrm{p}$ charge transfer band which may be intrinsic in the emission center. From this fact we can assume that the $2.2 \mathrm{eV}$ band is associated with electronic transitions in the non-bridging oxygen atom, modified by the presence of $\mathrm{Pb}$ atoms [11]. Accordingly, the emission and excitation bands of these transitions differ from those of the "classic" non-bridging oxygen atoms $(1.9 \mathrm{eV}$ emission band, $4.7 \mathrm{eV}$ excitation band, $\tau=$ $20 \mu \mathrm{s})$. The $5-8 \mathrm{eV}$ excitation of the $\mathrm{NBOHC} / \mathrm{Pb}$ luminescence leads to the slow kinetics. In the same region there are excitation peaks for the $2.6 \mathrm{eV}$ PL band of the localized $\mathrm{Pb}$ states. $\mathrm{Pb}$-related excitation of the $2.2 \mathrm{eV}$ band (Fig. 6) should contain the states of hopping electron transport over the conduction band thus slowing down the PL decay. The $3.75 \mathrm{eV}$ PLE band corresponds to the intrinsic excitation of the $\mathrm{NBOHC} / \mathrm{Pb}$ centers. Figure 5 shows that besides radiative relaxation, this defect may transfer the excitation energy to the triplet states of $\beta$ ODC:

$$
(\mathrm{Si}-\mathrm{O}-\mathrm{Pb})^{*} \Rightarrow\left\{\begin{array}{c}
(\mathrm{Si}-\mathrm{O}-\mathrm{Pb})+\mathrm{h} v \\
\beta-\mathrm{ODC}^{*}
\end{array}\right.
$$

Analogous processes have been observed earlier between $\alpha$-ODC and ordinary NBOHC centers in silica, [24]. Some part of excitation energy can be transfered to the $\mathrm{Pb}$ localized states, resulting in $2.6 \mathrm{eV}$ luminescence (Fig. 5) and vice versa (Fig. 6):

$$
(\mathrm{Si}-\mathrm{O}-\mathrm{Pb})^{*} \leftrightarrow \mathrm{LS} \mathrm{Pb}^{2+}
$$

The overall picture of possible emission, interpretation and the spectral characteristics of electron transitions are shown in Table 1 and in Fig. 9. As can be seen from the figure, three types of luminescence centers were identified: point defects like ODC and $\mathrm{NBOHC} / \mathrm{Pb}$, as well as lead localized states. Centers of $\beta$-ODC type show emission due to implementation of radiative transitions $T_{1} \rightarrow S_{0}$ and $S_{1} \rightarrow S_{0}$, energies of which are slightly modified by the presence of lead atoms in the $\mathrm{x}<<0.5$. Photoluminescence excitation for non-bridging oxygen is performed by the transfer of energy from $6 \mathrm{p}$ - states of lead atoms within the $\mathrm{PbO}$ $\mathrm{SiO}_{2}$ or $\mathrm{SiO}_{2}$ lattice. This luminescence corresponds to the transition of $\mathrm{Pb} 6 \mathrm{p} \rightarrow \mathrm{NBO} 2 \mathrm{p}$. 
According to [9], the NBO emission dominates in the $x \mathrm{PbO} \cdot(1-x) \mathrm{SiO}_{2}$ glasses with average composition values of $x \sim 0.5$, thus one can assume the existence of such centers in the transition zone from the $\mathrm{SiO}_{2}$ matrix to inclusions of $\mathrm{Pb}$. Luminescence in the spectral range of 2.3-2.8 eV is due to $\mathrm{Pb} 6 \mathrm{p} \leftrightarrow \mathrm{Pb} 6 \mathrm{~s}$ transitions between the tails states of energy bands in the $\mathrm{x}<0.5$ zone.

\section{Conclusion}

The characteristics of luminescent properties for silica films and glasses implanted with lead ions were studied. After ion-beam exposure the modified layers of the samples under study appear as "Pb-SiO $2 "$ nanocomposite, the oxide part of which is a complex microheterogeneous system with a composition formula $x \cdot \mathrm{Pb} \cdot(1-x) \cdot \mathrm{SiO}_{2}$, including a set of amorphous zones with different values of the composition factor $x=0 \div 1$.

The use of pulsed excitation by synchrotron radiation has allowed to establish the existence of different types of emission centers. The first group includes radiation-induced defects such as $\mathrm{SiO}_{2}$ matrix NBOs (in the structural fragments of $\mathrm{Si}-\mathrm{O}-\mathrm{Pb}$ ) and $\mathrm{ODCs}$ (oxygen-deficient centers), whose spectroscopic parameters are modified by the presence of lead ions in the near surrounding. Along with the implantation-related defects the luminescence of localized electronic states of energy band tails in the amorphous lead silicate microphase with composition factor $x \leq 0.5$.

For the $\mathrm{Pb}^{2+}$ localized states and discrete lead centers in silica films and glasses the factor of the local environment was determined on the basis of experimental spectroscopic data of the specified type. The distinction of local structure parameters for the luminescence centers in films and glasses are found. This difference may be caused by a lot of the reasons including unequal thermal history, implantation profiles, non-stoichiometry and also degree of non-uniform broadening of spectral bands.

\section{Acknowledgements}

The research was carried out in the framework of the RFBR (projects 13-08-00568 and 13-02-91333) and DFG (project FI 497/15-1). The work was partially supported by the Ministry of Education and Science of Russian Federation (the basic part of the government mandate). 


\section{References}

1. C. Flytzanis, F. Hache, M.C. Klein, D. Ricard and PH. Roussignol, in: Progress in Optics, Ed. E. Wolf, North Holland, Amsterdam, 1991.

2. R.H. Magruder III, R.A. Weeks, S.H. Morgan, Z. Pan, D.O. Henderson, R.A. Zuhr, J. Non-Crystalline Solids 192\&193 (1995) 546-549.

3. L.D. Bogomolova, V.A. Jachkin, S.A. Prushinsky, S.A. Dmitriev, S.V. Stefanovsky, Yu.G. Teplyakov, F. Caccavale, J. Non-Crystalline Solids 241 (1998) 174-183.

4. H.-J. Fitting, J. of Lumin. 129 (2009) 1488-1492.

5. P. Roth, G.W. Fraser, Nucl. Instr. and Meth. in Phys. Res. A 439 (2000) 134.

6. A.F. Zatsepin, E.A. Buntov, V.A. Pustovarov, and N.V. Gavrilov, Proc. of the XXI Int. Conf. ISI-2013. Yaroslavl, Russia, August 22-26, 2013, p. 124-126.

7. B. Ziberi, F. Frost, M. Tartz, H. Neumann, B. Rauschenbach, Thin Solid Films 459 (2004) 106-110.

8. D.A. Zatsepin, A. Hunt, A. Moewes, E.Z. Kurmaev, N.V. Gavrilov, I.S. Zhidkov, and S.O. Cholakh, J. Non-Cryst. Solids 357 (2011) 3381-3384.

9. A.L. Shakhmin, A.M. Tyutikov, Fizika i Khimiya Stekla 16 (1990) 833

10. A.F. Zatsepin, I.S. Zhidkov, A.I. Kukharenko, D.A. Zatsepin, M.P. Andronov, and S.O. Cholakh, Optical Materials 34 (2012) 807-811.

11. K.N. Dalby, H.W. Nesbitt, V.P. Zakaznova-Herzog, and P.L. King, Geochimica and Cosmochimica Acta 71 (2007) 4297-4313.

12. L. Skuja, J. Non-Crystalline Solids 239 (1998) 16-48.

13. A.F. Zatsepin, V.A. Pustovarov, V.S. Kortov, E.A. Buntov, H.-J. Fitting, J. Non crystalline solids 355 (2009) 1119-1122.

14. H.-J. Fitting, L. Fitting Kourkoutis, B. Schmidt, B. Liedke, E.V. Ivanova, M.V. Zamoryanskaya, V.A. Pustovarov, and A.F. Zatsepin, Phys. Status Solidi A 209 (2012) 1101-1108.

15. A.F.Zatsepin, H.-J.Fitting, V.S.Kortov, V.A.Pustovarov, B.Schmidt, E.A.Buntov, J. Non-Crystalline Solids 355 (2009) 61-67.

16. A.F. Zatsepin, E.A. Buntov, V.S. Kortov, V.A. Pustovarov, H.-J. Fitting, B. Schmidt, N.V. Gavrilov, J. of Surface Investigation. X-ray, Synchrotron and Neutron Techniques 6(4) (2012) 668-672.

17. A.F. Zatsepin, E.A. Buntov, V.A. Pustovarov, H.-J. Fitting, J. of Lumin. 143 (2013) 498-502.

18. A.F. Zatsepin, E.A. Buntov, V.S. Kortov, V.A. Pustovarov, H.-J. Fitting, J. of Spectroscopy and Dynamics 3 (2013) article 20.

19. E.A. Buntov, A.F. Zatsepin, V.S. Kortov, V.A. Pustovarov, H.-J. Fitting, J. Non- Crystalline Solids 357 (2011) 1977-1980.

20. G. Zimmerer, Radiat. Meas. 42 (2007) 859-864.

21. F. Seitz, J. Chem. Phys. 6 (1938) 150-162.

22. Q. Sun, B. Qu, J. Shi, Phys. Chem. Chem. Phys. 12 (2010) 4178-4183.

23. A. Ranfagni, D. Mugnai, M. Bacci, G. Viliani, M.P. Fontana, Advances in Physics 32 (6) (2006) 823-905.

24. A.F. Zatsepin, Phys. of the Solid State 52 (2010) 1176-1187. 


\section{Figures captions}

Fig. 1.

$\mathrm{Pb}^{+}$ion implantation into silica: a) normalized depth distributions of the implanted $\mathrm{Pb}$ ions in silica glasses (30 keV, red) and silica films (150 keV, blue);

b) scheme of radial-spatial distribution of emission centers in a $\mathrm{SiO}_{2}: \mathrm{Pb}^{+}$system.

\section{Fig. 2.}

Photoluminescence spectra of ion-implanted $\mathrm{SiO}_{2}: \mathrm{Pb}^{+}$glass excited with $\mathrm{hv}_{\mathrm{exc}}=6.89 \mathrm{eV}$ and measured at $\mathrm{T}=290$ (1) and $8 \mathrm{~K}(2)$. The different transitions are indicated.

\section{Fig. 3.}

PL decay kinetics of the $4.35 \mathrm{eV}$ PL emission band of $\mathrm{SiO}_{2}: \mathrm{Pb}^{+}$glasses under $5.08 \mathrm{eV}$ excitation pulse (filled curve).

\section{Fig. 4.}

PL excitation spectra for the 2.18, 2.76 and $3.06 \mathrm{eV}$ emission bands of the $\mathrm{SiO}_{2}: \mathrm{Pb}^{+}$glasses.

Filled curves are Gaussian components corresponding to the $\mathrm{A}, \mathrm{B}, \mathrm{C}$ and $\mathrm{D}$ transitions of the $\mathrm{Pb}^{2+}$ ion.

\section{Fig. 5.}

Time-resolved PL spectra of the $\mathrm{SiO}_{2}: \mathrm{Pb}^{+}$glasses under $3.76 \mathrm{eV}$ excitation, $\mathrm{T}=8 \mathrm{~K}$.

Time windows: fast $=0.8-18 \mathrm{~ns}$; slow $=52-140 \mathrm{~ns}$; stat $=$ integrated over full pulse repetition time up to $192 \mathrm{~ns}$.

\section{Fig. 6.}

Time-resolved excitation spectra of the $2.18 \mathrm{eV} \mathrm{PL}$ band in $\mathrm{SiO}_{2}: \mathrm{Pb}^{+}$glasses. Components of the spectra were normalized to unity; time windows see Fig 5.

\section{Fig. 7.}

Photoluminescence (PL) (a) and PLE excitation (b) spectra of ion-implanted $\mathrm{SiO}_{2}: \mathrm{Pb}^{+}$films, $\mathrm{T}=8 \mathrm{~K}$.

\section{Fig. 8.}

The dependence of the spectral position of the optical absorption bands A, B, C, D on the environmental factor $\mathrm{h}$, according to [9]. The dotted lines indicate the position of these bands in the excitation spectrum for $\mathrm{SiO}_{2}: \mathrm{Pb}$ glasses. The intersections of curves and straight lines give the average values of the environment factor for glasses (full circles, $h=0.41$ ) and films (open circles, $h=0.44$ 0.49). The inset shows the energy structure of the outer electron shell of an ion $\mathrm{Pb}^{2+}$. Transition $\mathrm{D}$ is not shown because it is related to the charge transfer.

\section{Fig. 9.}

Scheme of optical transitions in the $\mathrm{SiO}_{2}: \mathrm{Pb}^{+}$system under ultraviolet excitation. Bold arrows show PL excitation channels, thin arrows - radiative transitions.

\section{Table 1.}

Spectroscopic parameters of the PL and PLE bands in the $\mathrm{SiO}_{2}: \mathrm{Pb}^{+}$system, correlated to respective electronic transitions (below). 
a)

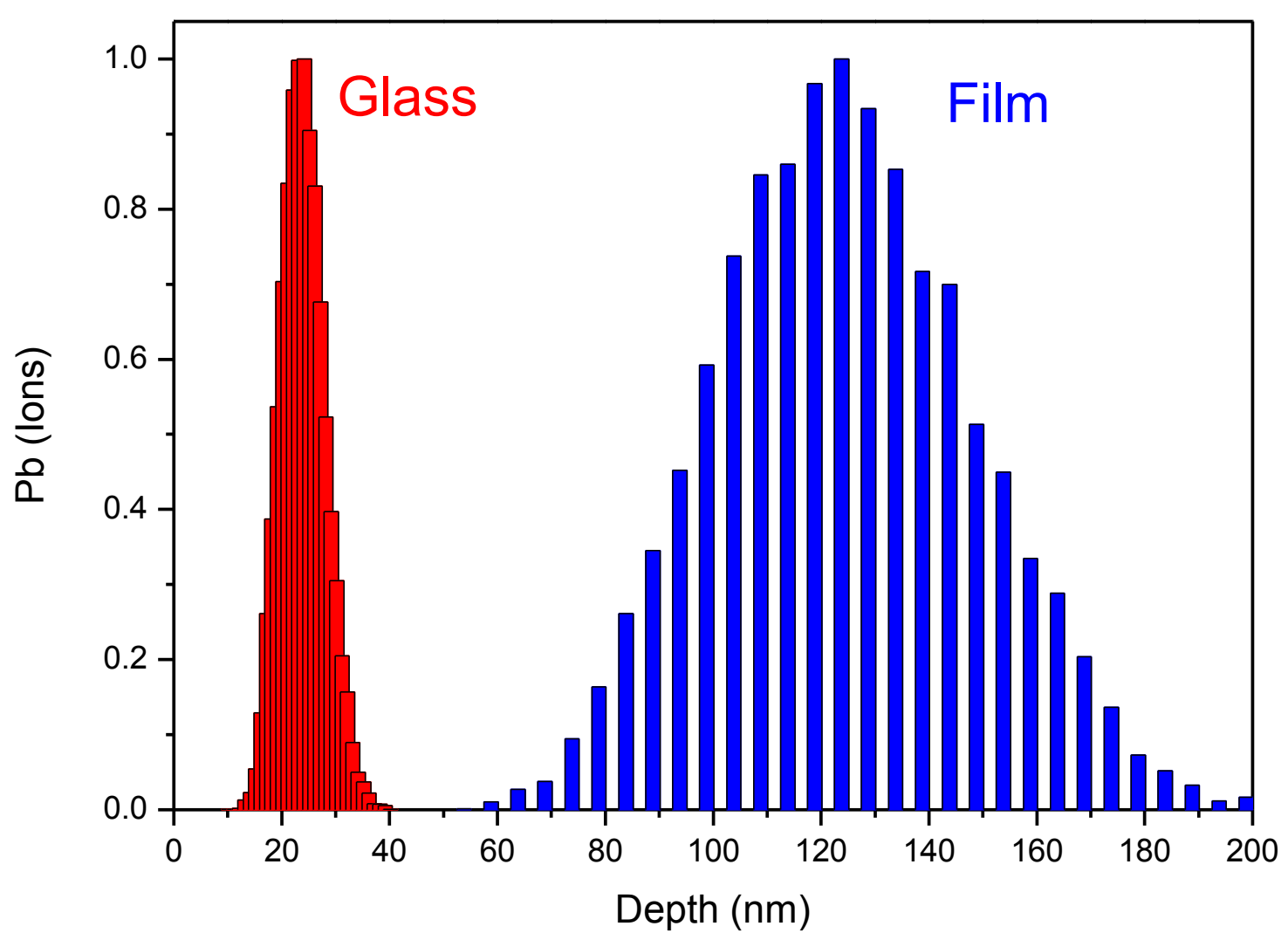

b)

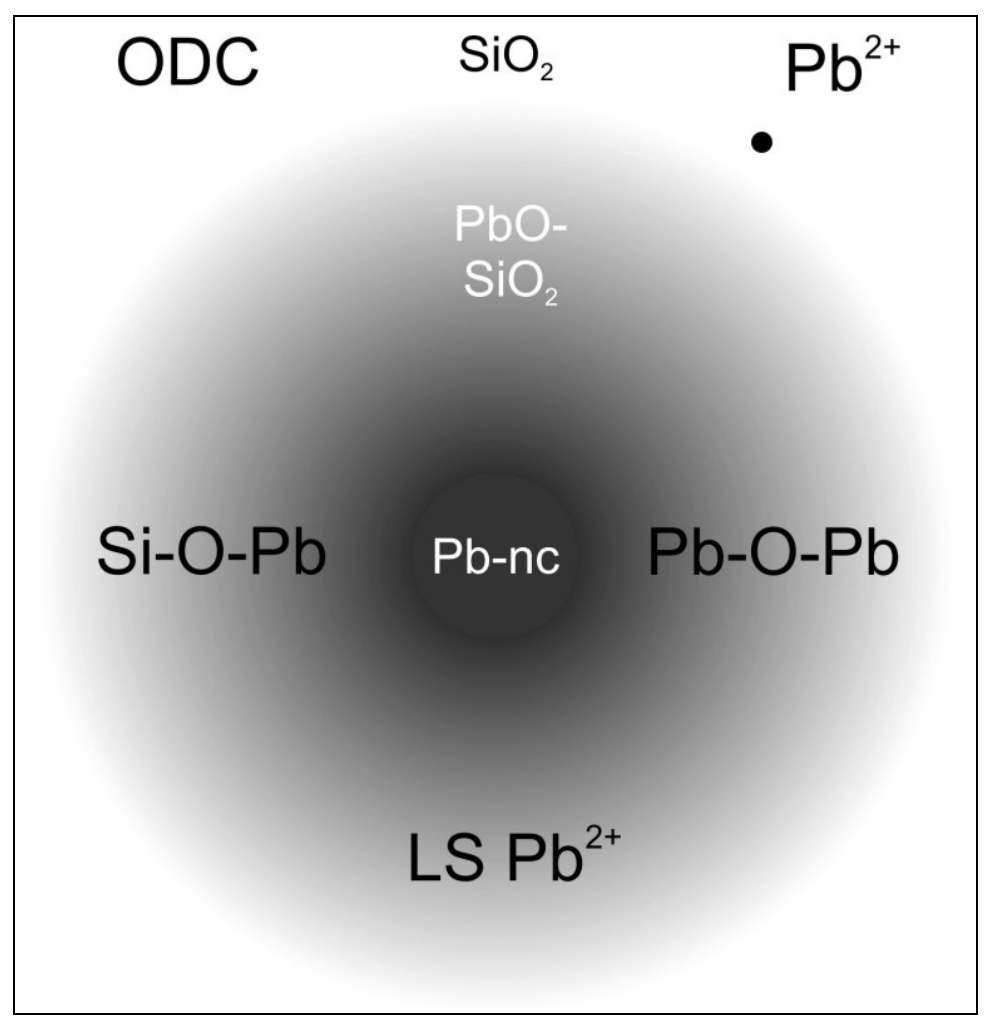

Fig. 1. 


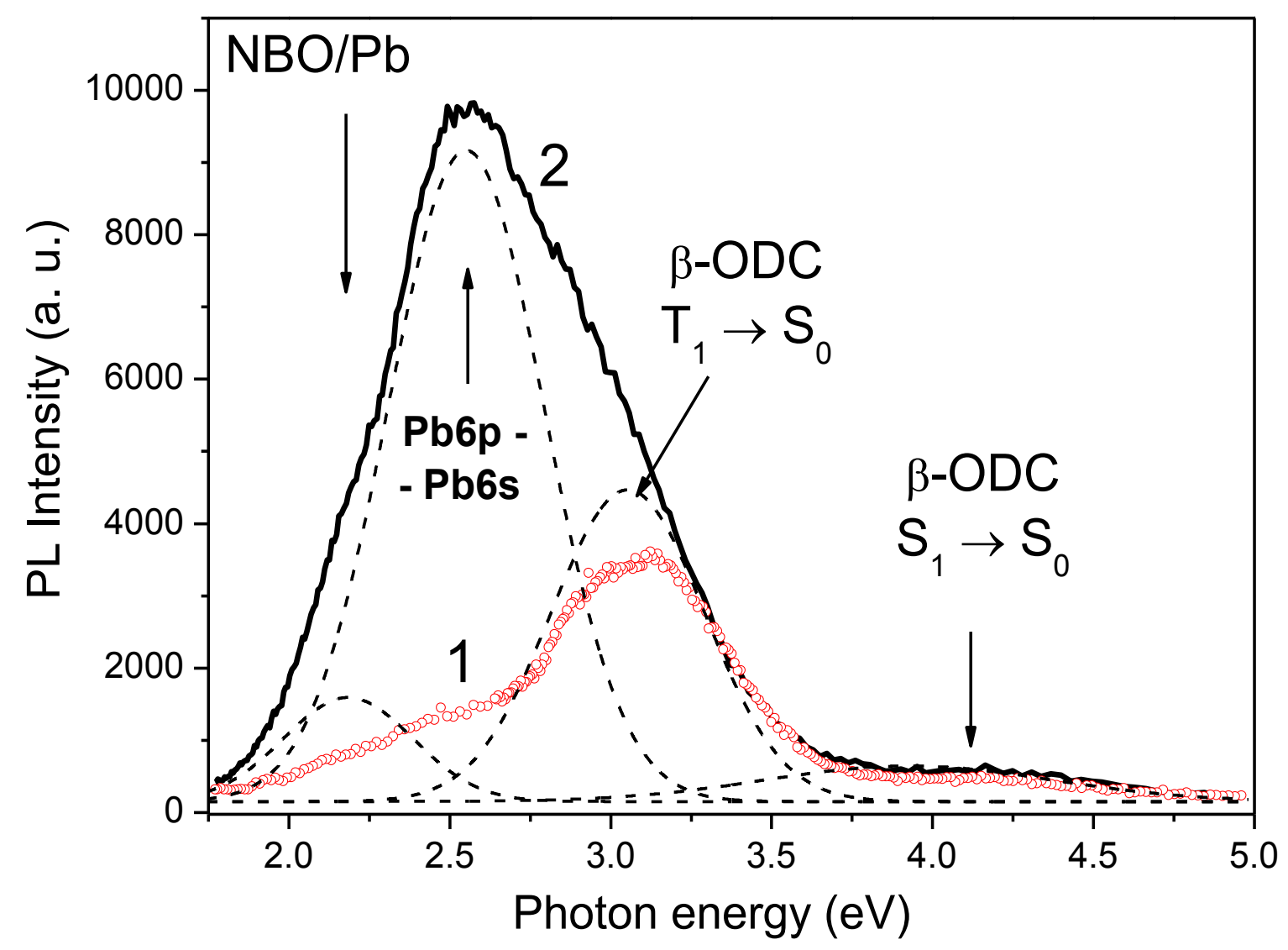

Fig. 2. 


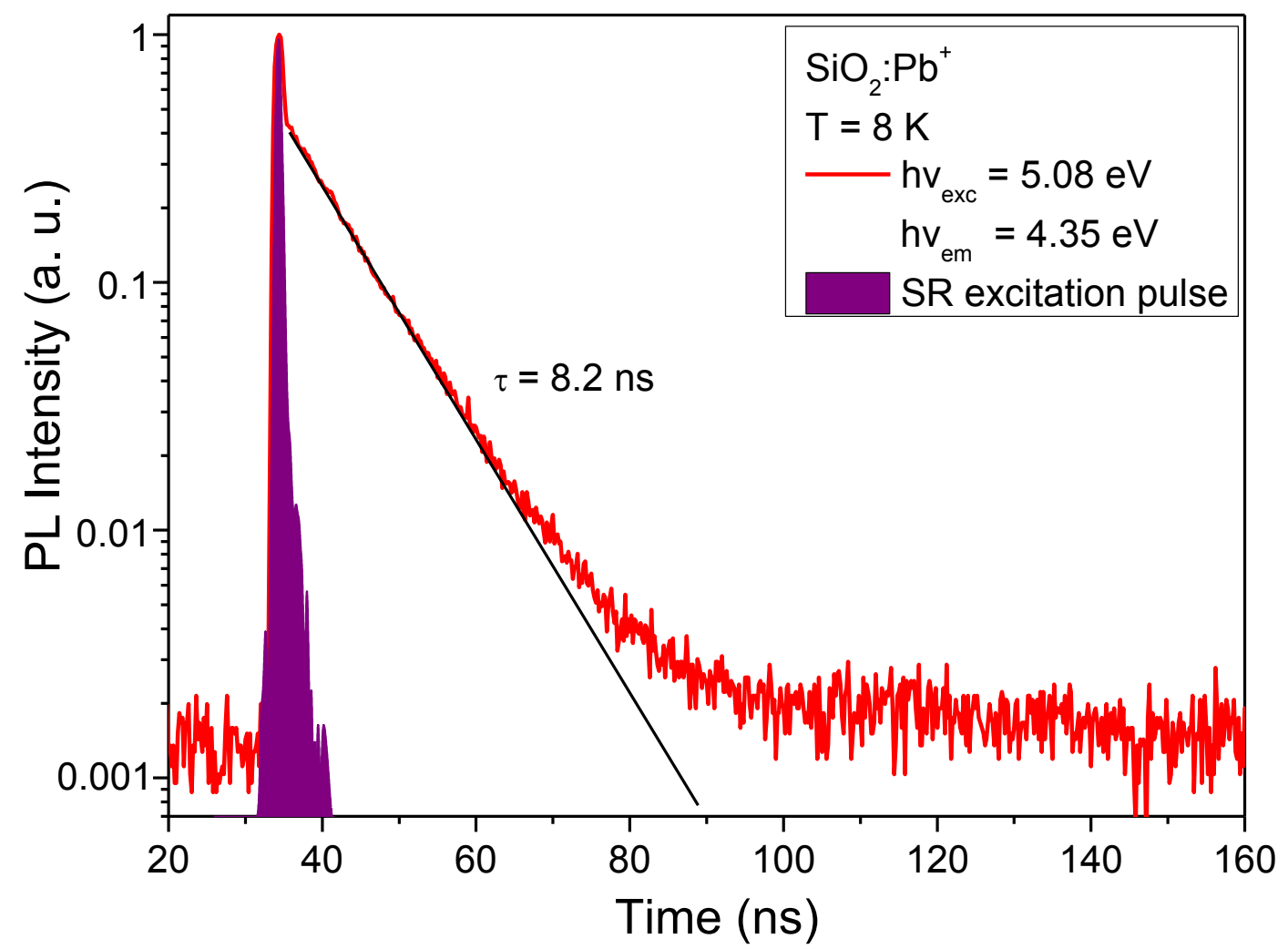

Fig. 3 


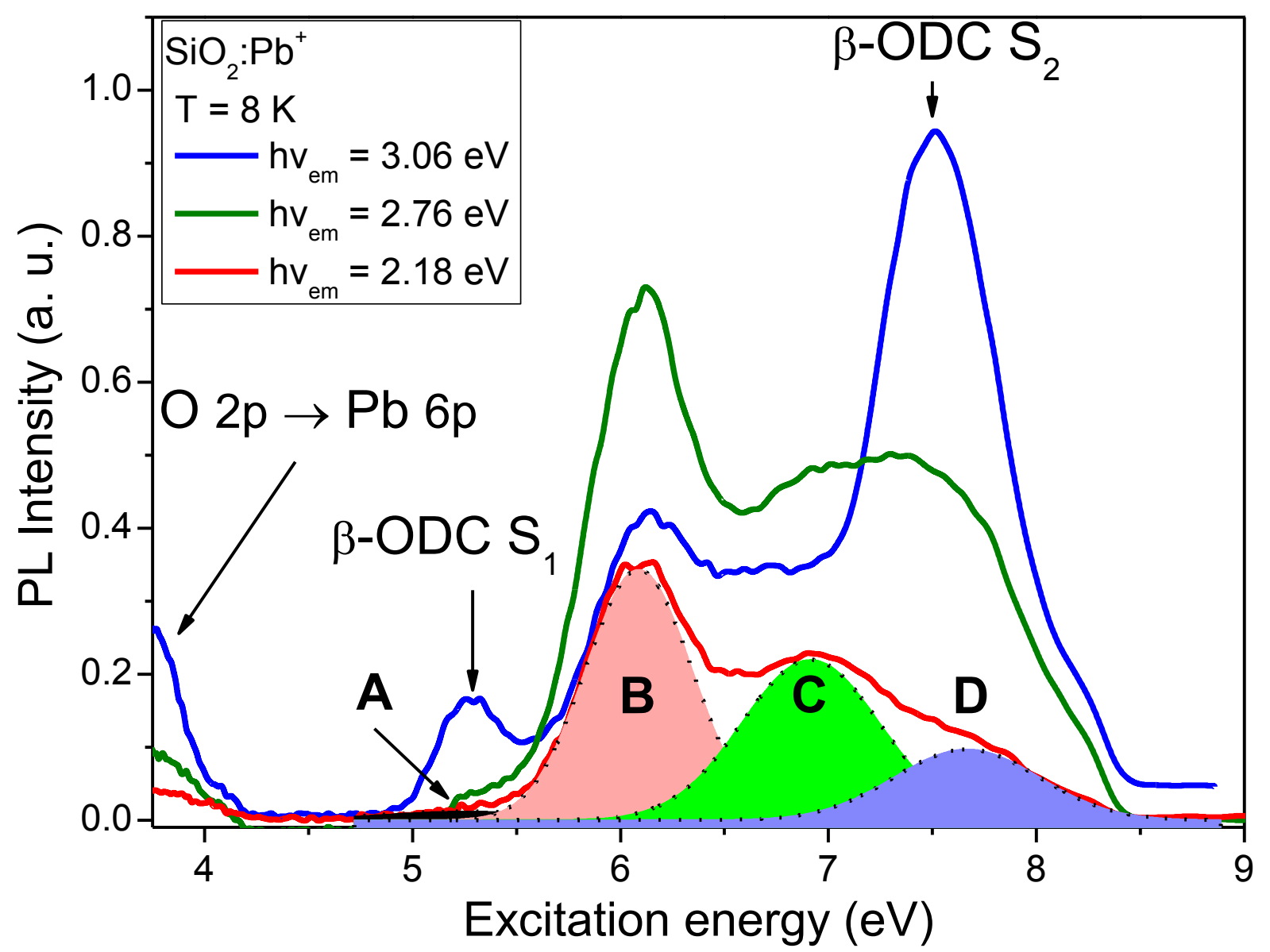

Fig. 4. 


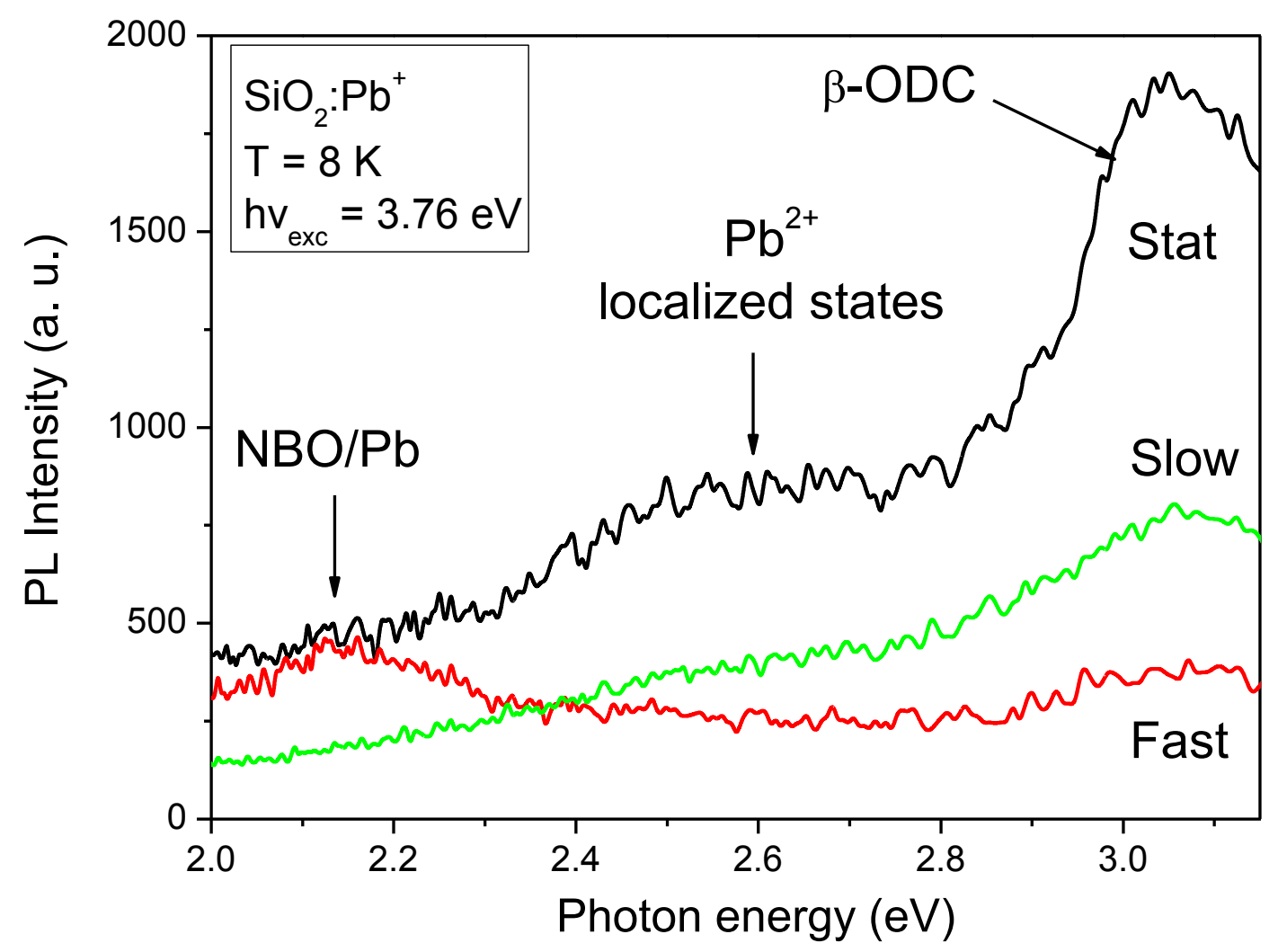

Fig. 5. 


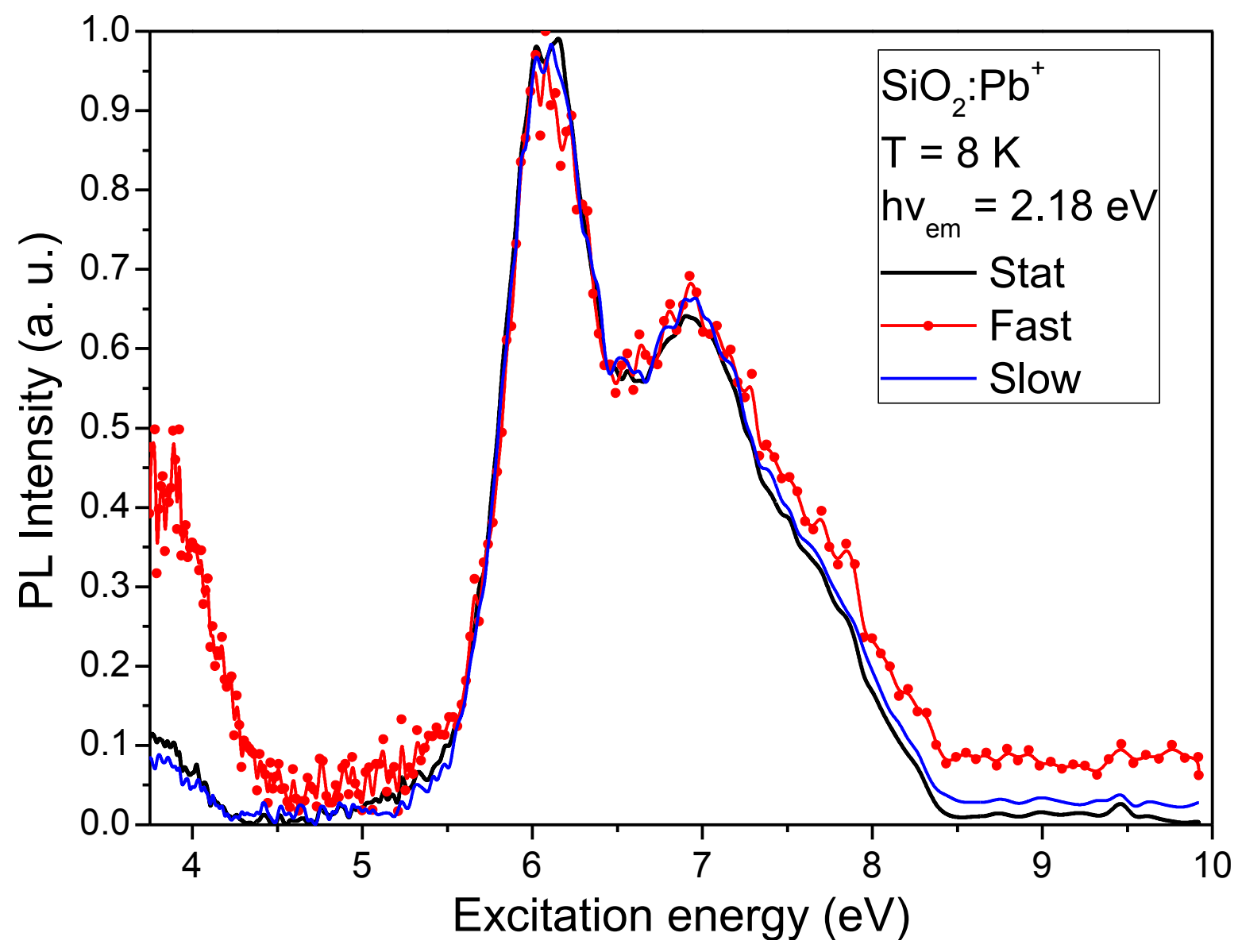

Fig. 6. 

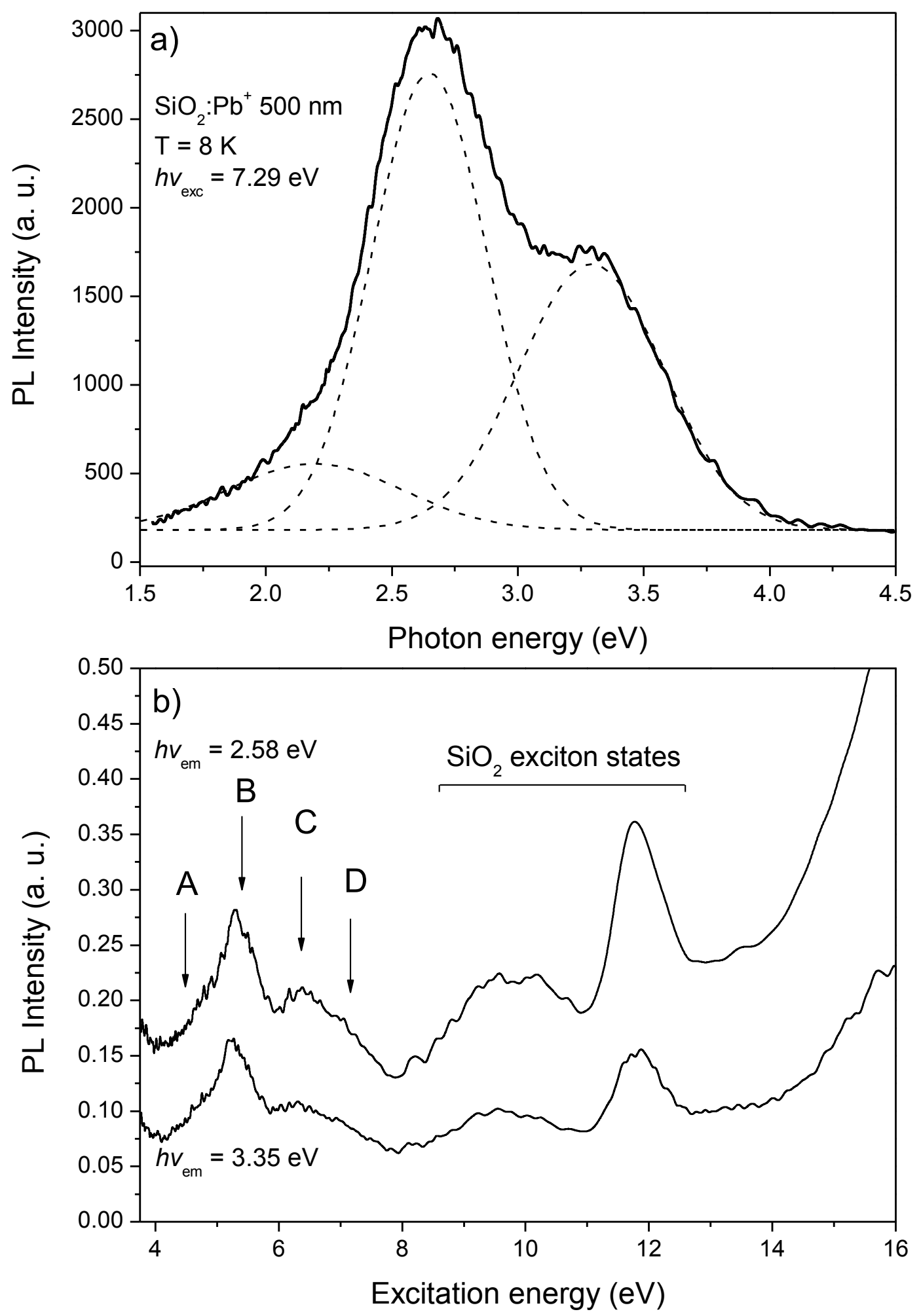

Fig. 7. 


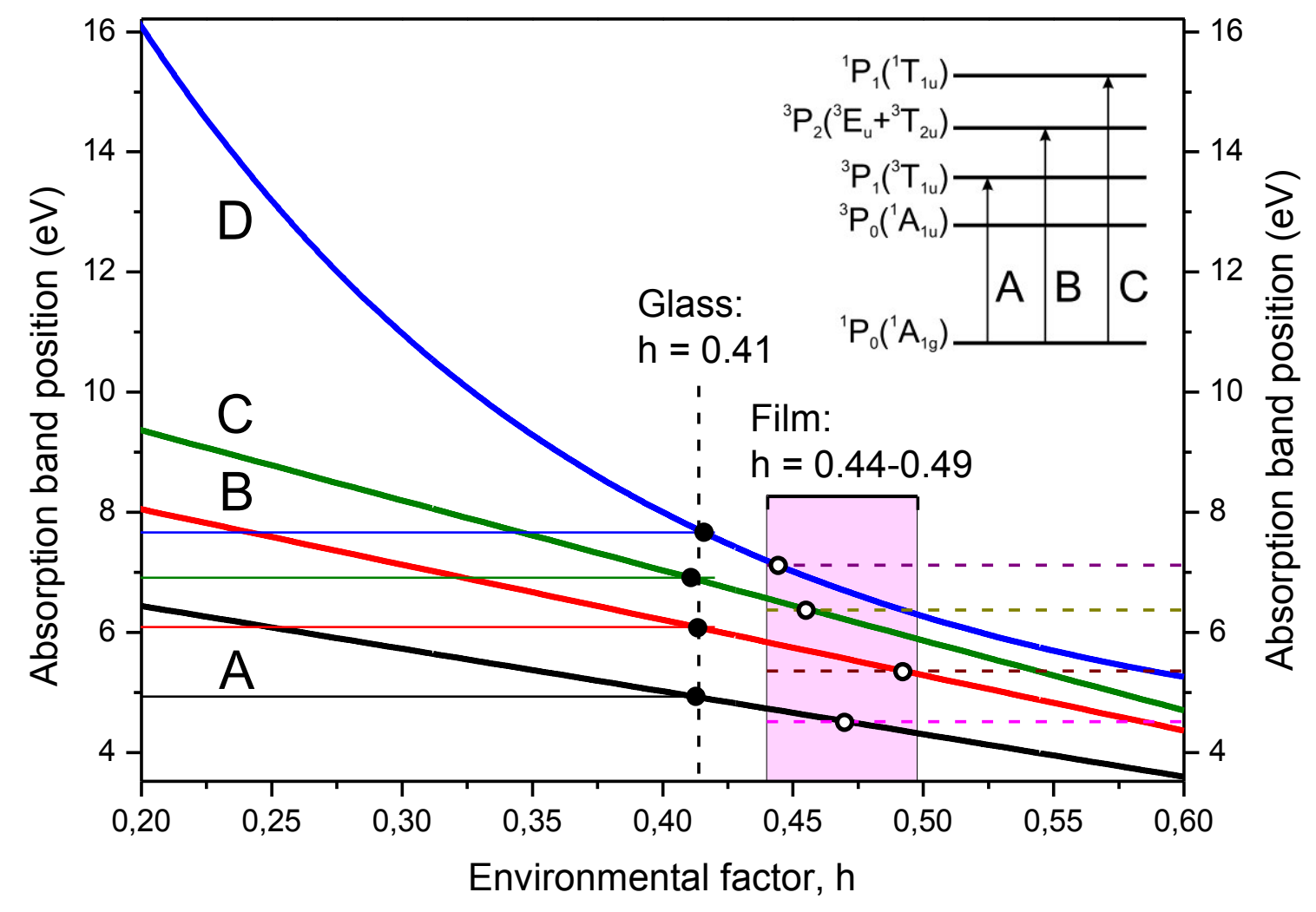

Fig. 8. 


\section{Excitation:}

A, B, C, D

$5-8 \mathrm{eV}$

$2.5 \mathrm{eV}$

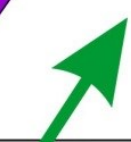

LS $\mathrm{Pb}^{2+}$

$\mathrm{Pb}$

$x \mathrm{PbO} \cdot(1-\mathrm{x}) \mathrm{SiO}_{2}$
$5.26 \mathrm{eV}$

$3.75 \mathrm{eV}$

$7.5 \mathrm{eV} 3.1 \mathrm{eV}$

$\mathrm{NBO} / \mathrm{Pb} \longrightarrow$ ODC

$\mathrm{X}$

Fig. 9.

$\mathrm{SiO}_{2}$ 
Table 1.

\begin{tabular}{|c|c|c|c|c|c|c|c|c|c|c|}
\hline \multirow{3}{*}{$\begin{array}{c}\text { Band type } \\
\text { Name } \\
h v_{\max } \\
(\mathrm{eV})\end{array}$} & \multicolumn{4}{|c|}{$\mathrm{PL}$} & \multicolumn{6}{|c|}{ PLE } \\
\hline & \multirow{2}{*}{$\begin{array}{l}\mathrm{CT} \\
2.18\end{array}$} & \multirow{2}{*}{$\frac{\mathrm{Pb}}{2.55}$} & \multicolumn{2}{|c|}{ ODC } & \multirow{2}{*}{$\frac{\text { CT }}{3.75}$} & \multicolumn{2}{|c|}{ ODC } & \multirow{2}{*}{$\frac{\mathrm{Pb}^{2+} \mathrm{B}}{6.09}$} & \multirow{2}{*}{$\frac{\mathrm{Pb}^{2+} \mathrm{C}}{6.91}$} & \multirow{2}{*}{$\frac{\mathrm{Pb}^{2+} \mathrm{D}}{7.67}$} \\
\hline & & & 3.06 & 3.93 & & 5.26 & 7.5 & & & \\
\hline $\begin{array}{c}\text { FWHM } \\
(\mathrm{eV})\end{array}$ & 0.47 & 0.56 & 0.55 & 1.03 & 0.50 & 0.30 & 0.6 & 0.51 & 0.66 & 0.70 \\
\hline Transition & $\begin{array}{l}\text { ते } \\
0 \\
0 \\
Z \\
\uparrow \\
\frac{2}{0} \\
0 \\
0\end{array}$ & $\begin{array}{l}n \\
0 \\
0 \\
0 \\
\uparrow \\
0 \\
0 \\
0 \\
0\end{array}$ & $\stackrel{\mathscr{n}}{\stackrel{\mathscr{1}}{=}}$ & $\begin{array}{l}\stackrel{\infty}{\uparrow} \\
\tilde{n}\end{array}$ & $\begin{array}{l}\text { ô } \\
0 \\
2 \\
\uparrow \\
\text { ते } \\
0\end{array}$ & $\begin{array}{l}\vec{n} \\
\hat{\uparrow} \\
\vec{n}\end{array}$ & $\begin{array}{l}\tilde{\hat{N}} \\
\hat{\tilde{N}}\end{array}$ & $\hat{n}_{\tilde{n}}^{\hat{n}^{N}}$ & 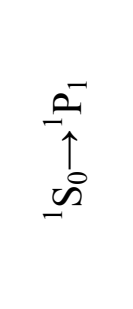 & $\underset{\underbrace{}}{\vartheta}$ \\
\hline
\end{tabular}




\section{Cover letter}

Dear Sirs,

we kindly ask you to publish our manuscript:

"Defect and Localized States in Silica Layers Implanted with Lead Ions"

in your Journal of Luminescence.

This paper shows investigation within the framework of a Russian-German cooperation.

With best regards,

Prof. Dr.Hans-Joachim Fitting

corresponding author 